\title{
OVERLAPPING SYNDROMES OFDERMATOMYOSITIS, SYSTEMIC LUPUS ERYTHEMATOSUS, AND RHEUMATOID ARTHRITIS: A CASE REPORT
}

Bruna Lindoso Correia ${ }^{1}$, Rafael Giovani Misse ${ }^{1}$, Alexandre Moura dos Santos ${ }^{1}$, Isabela Bruna Pires Borges ${ }^{1}$, Samuel Katsuyuki Shinjo ${ }^{1, *}$

1. Faculdade de Medicina FMUSP, Universidade de São Paulo, São Paulo (SP), Brazil.

*Corresponding author: samuel.shinjo@usp.br

1741: tem citações, mas não tem referências.

\section{BACKGROUND}

Overlapping syndromes are rare conditions in which patients satisfy classification criteria of at least two distinct connective tissue diseases. Herein, we report on a patient with overlapping syndromes simultaneously compounded by three systemic autoimmune diseases.

\section{CASE REPORT}

A 55-year-old white male presented initially with rash malar, photosensitivity, polyarthritis nonerosive, and non-nephrotic proteinuria. Laboratory data showed positivity to serum antinuclear factor, anti-dsDNA, anti-Ro and anti-La autoantibodies, and hypocomplementemia. The systemic lupus erythematosus (SLE) diagnosis was established (SLICC, 2021) and the patient received glucocorticoid, hydroxychloroquine, and immunosuppressive drugs with good outcome. After one year, the patient developed isolated symmetrical polyarthritis. A hand X-ray revealed erosive bone lesions, and laboratory data showed positive anticyclic citrullinated peptide; therefore, rheumatoid arthritis diagnosis (ACR/EULAR, 2010) was defined. Six months later, the patient showed new cutaneous lesions compatible with Gottron's sign, and predominantly proximal limb muscle weakness with serum levels of creatine phosphokinase ( $<1700 \mathrm{U} / \mathrm{L}$ ). Muscle biopsy revealed perimysium perivascular lymphomononuclear cell-infiltration. The DM diagnosis was defined (EULAR/ACR, 2017). Upon diagnosis, the patient received methylprednisolone pulse therapy ( $3 \mathrm{~g})$ and several immunosuppressive drugs and rituximab. This last drug promoted total disease remission. During the entire process, the patient also gradually began to complain of xerophthalmia and xerostomia, without defining diagnosis of Sjögren's syndrome.

\section{CONCLUSION}

Overlapping syndromes are rare conditions that should be considered in clinical rheumatologist practice. The present case shows treatment of a patient with three simultaneous rheumatic diseases with a good outcome.

\section{FUNDING}

FAPESP Grant No. 2019/11367-9 to IBPB, Grant No. 2019/12155-5 to RGM, and Grant No. 2019/11776-6 to SKS.

\section{KEYWORDS}

Dermatomyositis, Systemic lupus erythematosus, Rheumatoid arthritis, Systemic autoimmune myopathies, Myositis. 